\title{
Schwannoma of intermediate supraclavicular nerve: Case report
}

\author{
Raghavendra $\mathrm{H}^{1,{ }^{*}}$, Faisal Mujeeb ${ }^{1}$, Ashrith $\operatorname{Reddy}^{1}$, Sreevani ${ }^{1}$, Rama Krishna Bachu ${ }^{1}$, Samson Sujith Kumar ${ }^{1}$, \\ Leela Rani ${ }^{2}$, Varsha $\mathrm{KS}^{3}$, Swarna Latha ${ }^{4}$ and Kalyan Rao $\mathrm{T}^{3}$ \\ ${ }^{1}$ Department of Neurosurgery, ESIC Medical College and Super Speciality Hospital, Hyderabad-500038, Telangana, India \\ ${ }^{2}$ Department of Pathology, ESIC Medical College and Super Speciality Hospital, Hyderabad-500038, Telangana, India \\ ${ }^{3}$ Department of Anaesthesiology, ESIC Medical College and Super Speciality Hospital, Hyderabad-500038, Telangana, India \\ ${ }^{4}$ Department of Radiology, ESIC Medical College and Super Speciality Hospital, Hyderabad-500038, Telangana, India
}

\begin{abstract}
Schwannoma of supraclavicular nerve is very rare tumour occurring in head and neck region. This case is reported as a rare case of intermediate supraclavicular nerve schwannoma. A 48-year-old female patient presented to the outpatient department with right supraclavicular swelling for 5 years. She was diagnosed differently initially as having connective tissue neoplasm, tuberculous lymphadenitis, and granulomatous lymphadenitis by different surgeons. After all investigations, she was subjected to enucleation of mass and the histopathological report was suggestive of schwannoma. Post-op no neurological deficit was observed. She was discharged on fourth postoperative day.
\end{abstract}

Keywords: supraclavicular nerve; schwannomas; brachial plexus

*Corresponding author: Dr. Raghavendra H, Department of Neurosurgery, ESIC Medical College and Super Speciality Hospital, Hyderabad-500038, Telangana, India. Email: harpanahalli. raghavendra@gmail.com

Received 10 July 2017; Revised 01 September 2017; Accepted 12 September 2017; Published 20 September 2017

Citation: Raghavendra H, Mujeeb F, Reddy A, Sreevani, Bachu RM, Kumar SS, Rani L, Varsha KS, Latha S, Kalyanrao T. Schwannoma of intermediate supraclavicular nerve: Case report. J Med Sci Res. 2017; 5(4):139-141. DOI: http://dx.doi.org/10.17727/ JMSR.2017/5-26

Copyright: (C) 2017 Raghavendra H, et al. Published by KIMS Foundation and Research Center. This is an open-access article distributed under the terms of the Creative Commons Attribution License, which permits unrestricted use, distribution, and reproduction in any medium, provided the original author and source are credited.

\section{Introduction}

Schwannomas are rare tumours and high proportion of these develop in head and neck region [1]. They are benign nerve sheath tumours and only about $5 \%$ are supraclavicular in location, mostly arising from brachial plexus in this location [2]. Very rarely these arise from cervical plexus nerves in this location. They pose a great challenge to surgeon's due to their rare occurrence, complex anatomical location and initial misdiagnosis in most of the times [3].

\section{Case report}

A 48-year-old female patient presented with left supraclavicular swelling for 5 years. The size of the swelling increased gradually from that of a peanut to that of an orange. There is no history of trauma, fever or systemic illness in the past. She 
only complained of a visible smooth swelling in right supraclavicular region. No complaints of weakness or numbness or loss function of the ipsilateral upper limb. On examination, she had $10 \times 8 \mathrm{~cm}$, firm, mobile, non-tender, nonpulsatile swelling in the right supraclavicular region, lower border of the swelling was not reachable. Neurological examination of the upper limb was completely normal. Ultrasonography of local site suggested it to be either a neurogenic tumour or a lymph node not involving any vessel and not having any nerve entrapment. MRI scan of the head and neck region was suggestive of a lump measuring around $10 \times 8 \mathrm{cms}$ which was well defined, well circumcised, non-enhancing, homogeneous soft tissue density, oval shaped in right supraclavicular region displacing sub-clavian vessels and brachial plexuses (Figure 1a,b). Nerve conduction velocity study was normal.

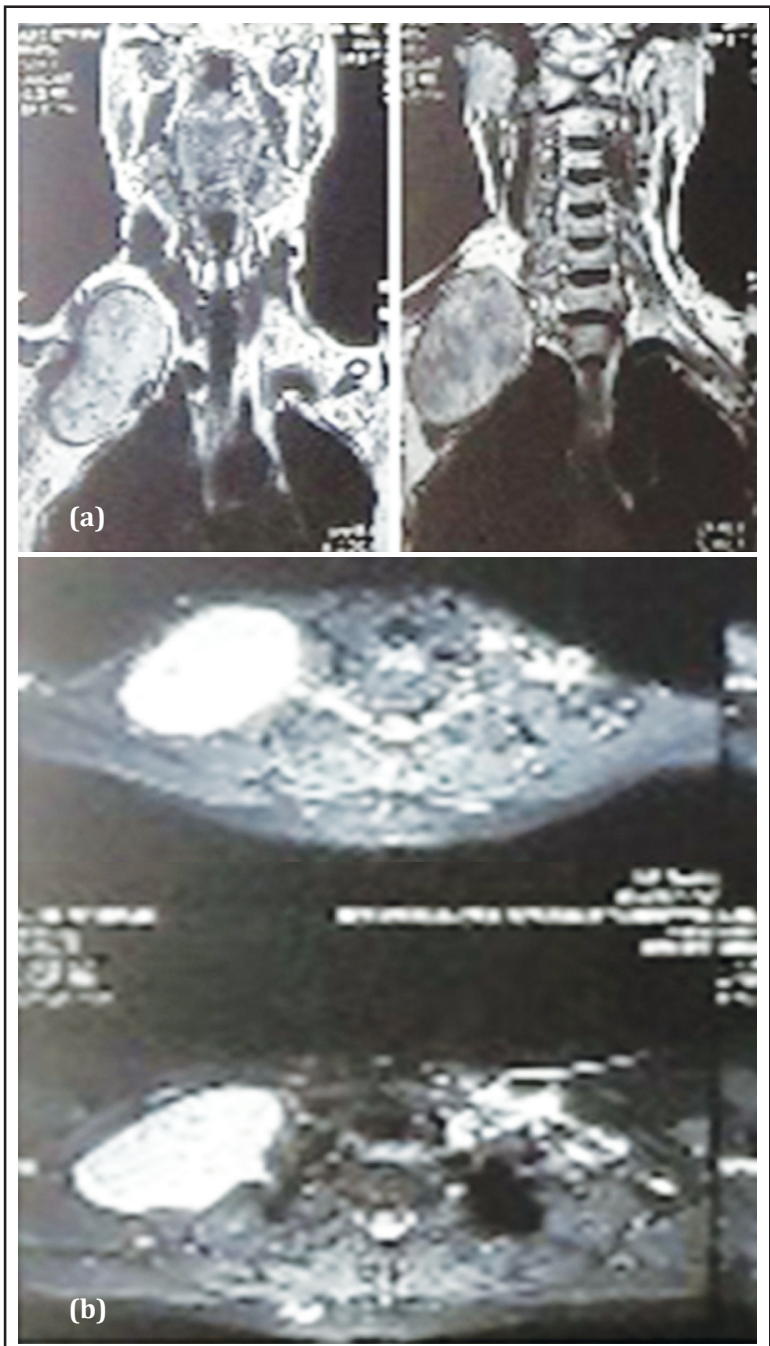

Figure 1a, b: MRI neck shows large well-defined mass lesion displacing subclavian vessels and brachial plexus.
Surgery was done under general anaesthesia and a lazy S shaped incision extending over the clavicle was made over the swelling. Incision deepened layer by layer, swelling was identified and separated from surrounding structures very carefully. Mass separated from the nerve sheath of the nerve passing beneath it carefully and was excised completely without any injury to the nerve (Figure 2). A suction drain was kept in situ.

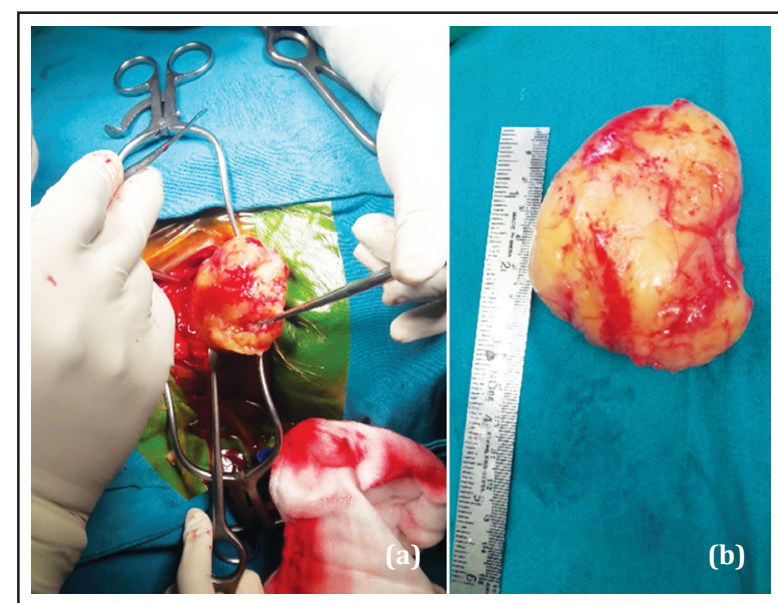

Figure 2: (a) Intra operative surgical mass enucleation, (b) Excised lump.

Specimen was sent for histopathological examination and the report suggested it to be a schwannoma (Figure 3). Post-operative period was uneventful with no residual neurological deficit in the ipsilateral upper limb. Patient is advised monthly follow up for the first one month and then 6 monthly follow up.

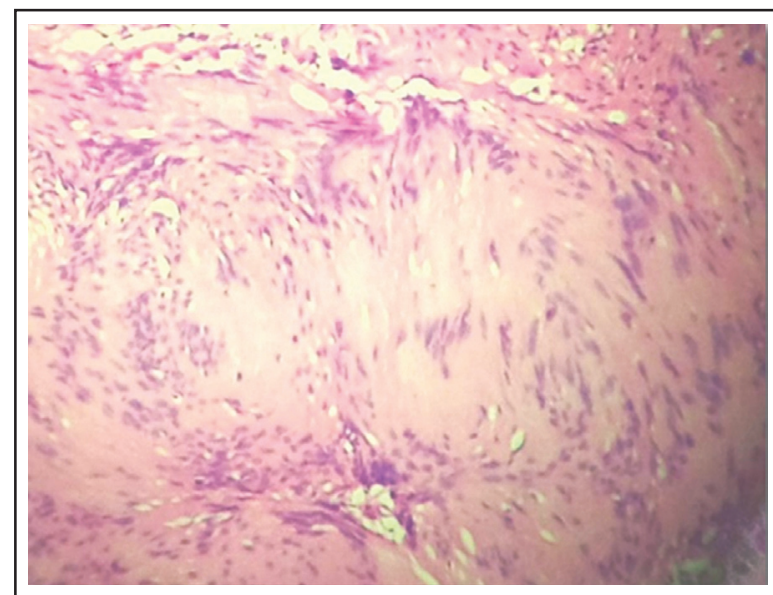

Figure 3: HPE suggestive of schwannoma.

\section{Discussion}

Schwannomas are benign, well encapsulated tumours arising from the nerve sheath [4]. Schwannomas 
usually present as local slow growing mass but may present with symptoms of nerve compression more commonly when arising from nerves of cervical plexus. Grossly these tumours are round, oval or plexiform and may appear yellow or gray [5]. They may occur at all ages but most commonly occur in second to fourth decade of life [6]. Surgery is indicated for tumours causing neurological deficit, discomfort, progressively growing lesions with a suspicion of malignancy and to prevent or minimize neural damage. Complete resection of these tumours with preservation of surrounding nerves should be the goal. Neural fascicles surrounding the schwannoma are usually separable and enucleation of the tumour is almost always possible. In our case we were also able to dissect the nerve fascicles and successfully excise the tumour with preservation of all the nerve fascicles. High suspicion and inclusion of this entity in the differential diagnosis of supraclavicular swellings is a must, for proper treatment of the patient.

\section{Conclusion}

Supraclavicular schwannoma is a rare entity and that too of middle supraclavicular nerve is very rare. Proper diagnosis of the lesion and information about the surrounding structures must be established before surgery, as it can be easily mistaken as an enlarged supraclavicular lymph node, which happened in our case and can result in an iatrogenic injury. Schwannoma should be included in the differential diagnosis of supraclavicular swellings and further management and surgery should be planned accordingly.

\section{Conflict of interest}

Authors declare no conflict of interest.

\section{References}

[1] Kumar A, Akhtar S. Schwannoma of brachial plexus. Indian J Surg. 2011; 73(1):80-81.

[2] Ahn KM, Lee HK, Lee KD, Yu TH. A case of neurilemmoma of the brachial plexus. J Korean Otolaryngol. 2002; 45(7):733735.

[3] Gajbhiye AS, Surana KM, Raj NSD, Varty G. Middle supraclavicular nerve schwannoma. Int Surg J. 2015; 2(2):267-269.

[4] Ganju A, Roosen N, Kline DG, Tiel RL. Outcomes in a consecutive series of 111 surgically treated plexal tumors: a review of the experience at the Louisiana State University Health Sciences Center. J Neurosurg. 2001; 95(1):51-60.
[5] Huang JH, Samadani U, Zager EL. Brachial plexus region tumours: a review of their history, classification, surgical management and outcomes. Neurosurgery Q. 2003; 13(3):151-161.

[6] Subhashish D, Kalyani R, Harendra Kumar ML. Vulval Schwannoma: a cytological diagnosis. J Cytol. 2008; 25(3):108-110. 